\title{
AIR AMBULANCE DRONE - A MODERN CONCEPTUAL AERIAL VEHICLE FOR SURVEILLANCE AND CASUALTY EVACUATION
}

\section{SENTTHIL KUMAR NJ, MANO S \& SREEHARI VM}

School of Mechanical Engineering, SASTRA Deemed to be University, Thanjavur, Tamil Nadu, India

ABSTRACT
The present works discuss the design of an Air Ambulance Drone (AAD), anuncrewed aerial vehicle or UAV has the ability
to perform an operation to handle numerous activities like vigilance, saving people, any unpleasant circumstances and
evacuation of wounded. The computations of Preliminary design of the present AAD had been summarized in detail, which
includes the structural, propulsive, aerodynamic and performance aspects. The innovative AAD employs the numerous
techniques that identify the survivor, final design and so on, had been deliberated in these researches. The design has been
made in Fusion 360 software and is presented. The peculiarities, significance and applications of present AAD have been
discussed.
KEYWORDS: Air Ambulance Drone, Casualty Evacuation \& Rescue

Received: May 10, 2019; Accepted: Jun 1, 2019; Published: Sep 06, 2019; Paper Id.: IJMPERDAUG2019144

\section{INTRODUCTION}

AAD or Air Ambulance Drone is a kit for first aid, which is low altitude and medium-range. An uncrewed aerial vehicle or UAV has the ability to perform an operation to handle numerous activities like vigilance, saving people, any unpleasant circumstances and evacuation of casualties, theserescue life in the region such as the region of war, to perform saving secretly, roadways, channels (waterways), and so on. The forecasted files of AAD are through a subset of V/STOL. So that, this could be raised and landing in a free space, nearby the patient. The forecasted buzzes are customized, which is employed to distribute in the incidence of unpleasant circumstances. These hold a digital dedicated controller, compacted defibrillate, patent medicine, trolley, breathing apparatus and also the other necessary materials are transported during unpleasant circumstances. The forecasted AAD is planned extra ordinarily UAV, which conveyances damaged entities in a health emergency, overdividing or area, impracticable for a regular ground hospital wagon. Due to the delay of ambulance or hospital wagon, people may die. So, the forecasted system of $\mathrm{AAD}$ is the greatest technique through which a casualty or patient in the problematic territory had been rescued.

In the situation of a battle or physical attack of militant or a nuclear spilling, the serious missionis employed to view for endure, attainment of wounded soldiers etc. Obviously, it will be difficult for doctors or other persons to enter such terrains, and AAD is very important in such cases. The signs of life had been predictable in the initial step. Getting key indications of soldier or citizensis the second step, and utilizes these to line up the individuals who are in consideration requirement, mostly. If the savers recognize who is alive in advance, the saving would be effective supplementary and life signs could be rescued additionally. The life signs of the individuals had been recognized through thermal imaging cameras. 
The detection for Personnel is tremendously a significant mission due to the developing concern, which regards safety and vigilance. The forecasted AAD was armed throughthe motion of radar that uses Doppler effects. These radars detect the basic structure which conveys a signal wave continuously that monitors the chest expansion or contraction of the individuals and assesses the rate of breath. Through these, the individual persondies or alive had been described. The AAD is also armed through the additional procedure as the radar that uses Doppler effects for the technology of heart sense. These proposed techniques had been employed when a soldierwas exhausting a guard. It also consist an infra-red camera, in which, an image had been formed. These formations aresubjected to IR or infrared radiation (Setjo et al., 2017). The detection for Personnel is tremendously a significant mission for defense force, BP or border patrol and the operations of SAR or search-and-rescue due to the developing concern, which regards safety and vigilance. (Li et al., 2016; Chuantao et al., 2015). The initial step is the proposed AAD, which holds a program for identification of human proximity, and tracking that employs ultra-wide-band impulse-based radar that uses Doppler effects(Li et al., 2012). In addition, it encompasses a radio sensor system. The human and other creatures are identified through these systems(Zhong et al., 2016). Then, it holds an innovative procedure for the identification of human proximity that employs millimeter-band sensors, which is static(Nanzer and Rogers, 2007). This technique, centerson describing a person who is lying or standing from a stage of movement, in a chaotic condition of open-air.

Thus, the purpose of the existing work is to progress the proposal of an innovative uncrewed aerial vehicle or UAV, having the ability to perform an operation to handle numerous activities likevigilance, saving people, any unpleasant situation and evacuation of casualties. The estimations and final design for the novel AAD had been described in this paper. Section 2 presents asignificant mathematical computation for the design, approximately. Section 3 presents the components and the final proposal of AAD in detail.

\section{PRELIMINARY DESIGN CALCULATIONS OF PRESENT AAD}

Some of the basic calculations performed to bring up a proper design of AAD like structural, aerodynamic, propulsive, weight estimation, etc. are presented in this section.

\subsection{Structural Calculations}

The $60 \times 40 \times 2 \mathrm{~mm}$ of stainless or inox steel, which is square and hollow in shape of section or square rod had been employed to construct the frame. The elliptical frames had been formed through bending these rods. The $40 \times 20 \times 2 \mathrm{~mm}$ of twelve stainless steel which is a square and hollow section is employed to build the stringers, whose length is $1829 \mathrm{~mm}$ stretched. The $2 \mathrm{~mm}$ of the thickness of the $\mathrm{Al}$ sheet is employed to develop a skin. Table 1 displays the fuselage dimensions.

Consider the elliptical cross-sectional shape, the outer area of AAD can be calculated as shown below by the Equation 1:

$$
\begin{aligned}
\text { Curved surface area } & =\pi \times H \times(A+B) \\
& =\pi \times 1829 \times(1219+762) \\
& =11382800 \mathrm{~mm}^{2}
\end{aligned}
$$

where,

Height is denoted as $\mathrm{H}$,

The axis of the semi-major axis is denoted as A, 
The axis of Semi-minor axis is denoted as B.

Thus, the $11382800 \mathrm{~mm}^{2}$ area, the $\mathrm{Al}$ sheet had been distributed throughout.

The entire volume of the fuselage is calculated through Equation 2:

Volume $(\mathrm{V})=\pi \times H \times A \times B$

$$
\begin{aligned}
& =\pi \times 1829 \times 1219 \times 762 \\
& =5.337 \times 10^{9} \mathrm{~mm}^{3}
\end{aligned}
$$

The fuselage total surface area is estimated through Equation 3:

Total Surface Area $=(\pi \times(A+B) \times H)+(2 \times \pi \times A \times B)$

$$
\begin{aligned}
& =(\pi \times(1219+762) \times 1829)+(2 \times \pi \times 1219 \times 762) \\
& =17219100 \mathrm{~mm}^{2}
\end{aligned}
$$

The NavieEuler formula is employed to estimate the fuselage perimeter, and given through Equation 4.

$$
\begin{aligned}
\mathrm{P} & =2 \pi \sqrt{ }\left(A^{2}+B^{2}\right) \\
& =2 \pi \sqrt{ }\left(1219^{2}+762^{2}\right) \\
& =6386950 \mathrm{~mm}^{2} .
\end{aligned}
$$

The extreme and free weight has been determined significantly. So that, its propeller, components of electronics and so on had been decided. The weight had been contributed through the mainframe, the main body of the aircraft, components of electronic, electrical engines and the base of the trolley through cabins. So that, the free weight had been estimated and attained around $700 \mathrm{~kg}$. Also, the pilot weight, casualty or attendant has to be added. We got $1000 \mathrm{~kg}$ aroundand displayed in Table 2. The $1500 \mathrm{~kg}$ (1.5 ton) of extreme weight lifting performance of the forecasted AAD had been attained through adding $50 \%$ of a factor of safety.

Table 1: Fuselage Dimensions

\begin{tabular}{|l|c|}
\hline \multicolumn{1}{|c|}{ Components } & Dimensions \\
\hline Fuselage Major Axis & $2438 \mathrm{~mm}$ \\
\hline Fuselage Minor Axis & $1524 \mathrm{~mm}$ \\
\hline Fuselage Height & $1829 \mathrm{~mm}$ \\
\hline
\end{tabular}

Table 2: Weight Distribution of the Proposed AAD

\begin{tabular}{|l|c|}
\hline \multicolumn{1}{|c|}{ Components } & Approximate Weight (kg) \\
\hline Fuselage & 300 \\
\hline Mainframe with landing gear & 202 \\
\hline Stretcher base & 45 \\
\hline Stretcher & 40 \\
\hline Propeller motors (16 motors) & 62 \\
\hline Motor battery & 20 \\
\hline Power circuit battery & 20 \\
\hline Air conditioner & 30 \\
\hline Casualty & 100 \\
\hline Lifesaving equipment & 20 \\
\hline Others Total & 13 \\
\hline
\end{tabular}




\subsection{Aerodynamic and Propulsive Calculations}

As per Equation 5, the required thrust for the forecasted AAD had been estimated.

$$
V_{i}^{2} \times 2 \times \rho \times A_{R o t}=T
$$

Where, inlet velocity had been denoted as $V_{\mathrm{i}}$, theair density had been denoted as $\rho$ and a rotor area had been denoted as $\mathrm{A}_{\mathrm{Rot}}$.

The required power for the forecasted AAD had been estimated as per the Equation 6.

$$
P_{r e q}=T \times V_{i}
$$

where,

In let velocity had been denoted as $V_{\mathrm{i} \text { and }}$ the required thrust for AAD had been denoted as $T$

The extreme power of the battery can supply at various throttle percentage for the developed AAD. So that, the $1000 \mathrm{~kg}$ of payload had been lifted and calculated through the Equation 7.

Power available at various throttle percentage $=42 \times 3.7 \times \mathrm{N} \times 154$

Where, $\mathrm{N}=$ Throttle percentage
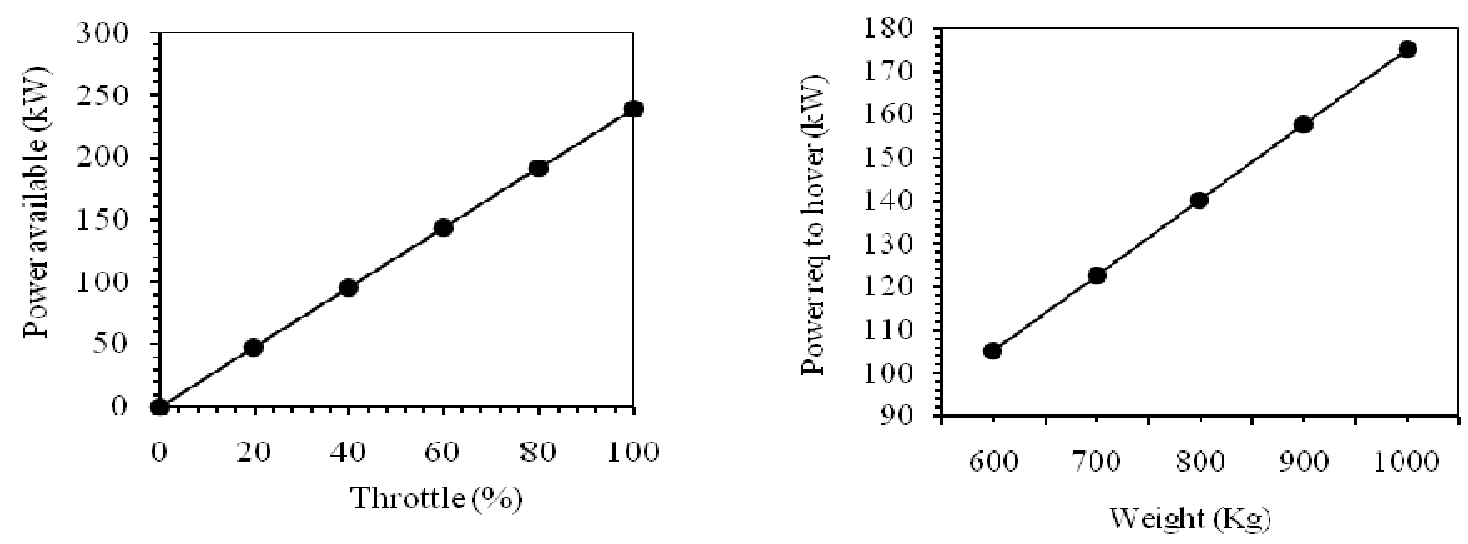

Figure 1(a): Power Available at Various Throttles. Figure 1(b): Power Required at Various Weights.

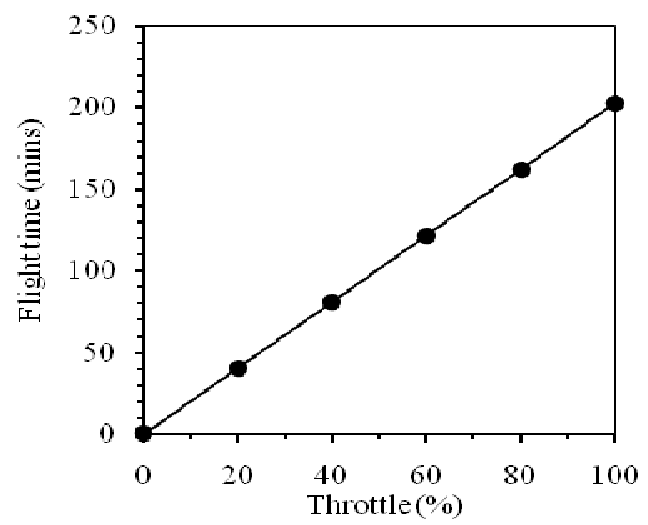

Figure 1(c): Flight Time at Various Throttles.

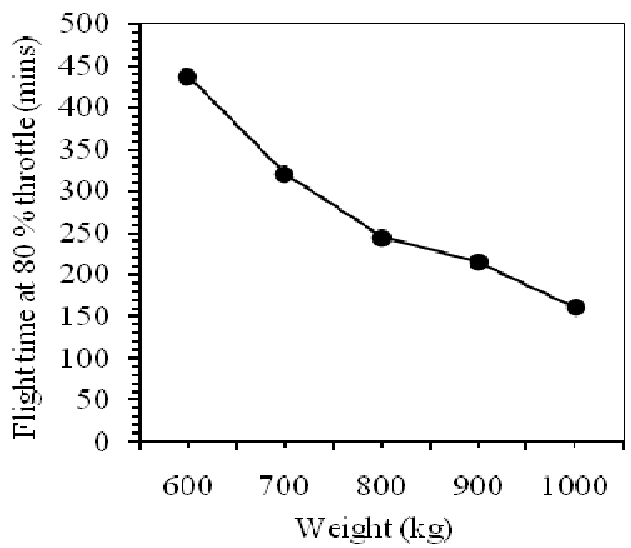

Figure 1(d): Flight Time at Various Weights. 
Table 3: Mission Specifications

\begin{tabular}{|l|c|}
\hline \multicolumn{1}{|c|}{ Specifications } & Calculated Value \\
\hline Power Required for level flight & $200.384 \mathrm{~kW}$ \\
\hline Cruise Velocity & $40 \mathrm{~m} / \mathrm{s}$ or $11.1 \mathrm{Km} / \mathrm{hr}$ \\
\hline $\mathrm{C}_{\mathrm{T}}$ & 1.866 \\
\hline Thrust & $5009.7 \mathrm{~N}$ \\
\hline $\mathrm{C}_{\mathrm{L}}$ & 0.371 \\
\hline $\mathrm{C}_{\mathrm{D}}$ & 1.86 \\
\hline $\mathrm{C}_{\mathrm{L}} / \mathrm{C}_{\mathrm{D}}$ & 0.2 \\
\hline Range & $35 \mathrm{~km}$ \\
\hline Endurance & $141 \mathrm{~ns}$ \\
\hline
\end{tabular}

Based on the above given Equation 7, the power available at various throttle percentage is plotted in the Figure 1a. It is observed from the graph that the power available from the battery varies linearly with throttle percentage from $0 \%$ to $100 \%$. The graph reaches a maximum value at $100 \%$ throttle. This graph depicts the maximum power the battery can supply at various throttle percentage for the proposed AAD in order to lift the payload of $1000 \mathrm{~kg}$. The power required by the AAD to hover at various weight distributions is given by the Equation 8 .

\section{Power required to hover $=$ Weight $* \mathrm{C}$}

Where, $\mathrm{C}=$ Discharge rate

Based on the Equation 8, a graph is drawn between weight inclusive of payload and the power required to hover, as shown in Figure.1b. The graph shows that the power required for hovering increases gradually with weight.

As per the Equation 9, the time of the flight for the forecasted AAD had been estimated.

$$
\text { Endurance }=\frac{\text { Power available at } 80 \% \text { throttle }}{\text { Power required to hover }} \times 60
$$

The Figure.1c and 1d show the variation of the endurance at various conditions. Figure 1c shows the relationship between the flight times at various throttle percentage. The Figure 1d depicts the relationship between weight and flight time at $80 \%$ throttle.

The formulas for the coefficient of pressure and coefficient of the thrust are given below in Equation 10.

$$
\mathrm{C}_{\mathrm{p}}=\frac{P}{\rho A_{R o t}(\Omega R)^{3}} \text { and } \quad \mathrm{C}_{\mathrm{T}}=\frac{P}{\rho A_{R o t}(\Omega R)^{2}}
$$

As per theformula which is shown above, the values had been attained subsequently. Table 3 display these values.

\section{DETAILED DESIGN AND MODELLING OF PRESENT AAD}

\subsection{Fuselage Design}

The fuselage is a hollow and elliptical cylinder in shape. This contains casualty and helping equipment of life for the directattention of medicine. The trolley base and the cockpit are involved in this fuselage. Then the edges had been combinedthrough componentslongitudinally, which islightweight, known as stringers (Figure 2). The skin is employed to secure these components. The Al sheet, which is added on throughen grossing completely and by holding its supports through welding or superior glues (Figure 3). 


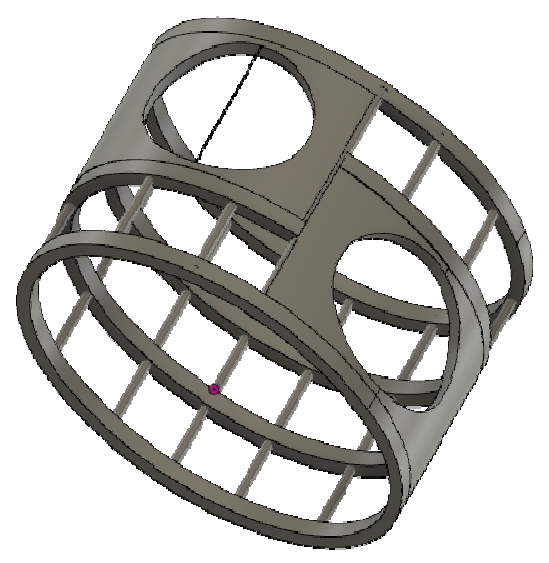

Figure 2: Fuselage with Frames and Stringers.

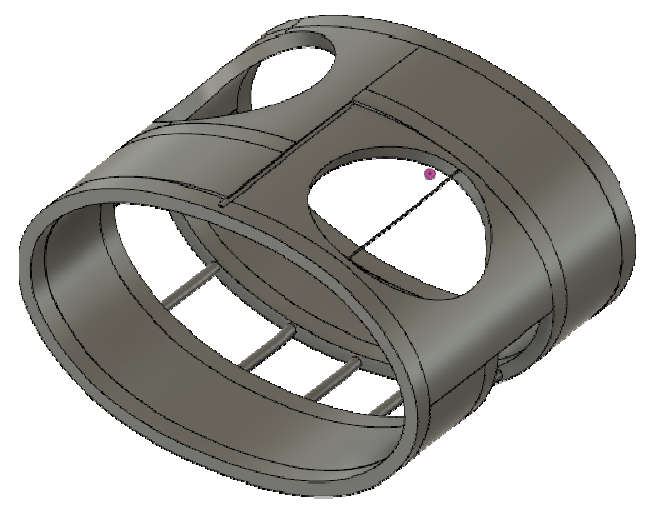

Figure 3: Casings and Stringers Secured with the Sheet Metal.

\subsection{Stretcher Base}

The trolley had been rested over thebase of the trolley or stretcher. The casualty had been rested over the trolley and the medicinal treatment had been given. The $2300 \times 600 \times 600 \mathrm{~mm}$ of dimension is the base of the stretcher. The $450 \mathrm{~mm}$ of three rods had been included in themiddle of the trolley. All together, combined to form the AAD's base of the trolley. The shack had been made through the free space below the trolley. These cabins contain all the required equipment like an oxygen tank, defibrillate, breathing apparatus, and so on that save the lives.

\subsection{Main Frame}

The eight hollow rods generally cylindrical in shape had been included in the mainframe. These are octagonally inclined through each other at a $45^{\circ}$ of the angle and measures in diameter of $4000 \mathrm{~mm}$. This each rod isfused of the dimension of $1800 \times 1800 \times 2 \mathrm{~mm}$ to the middle of a square orfour-sided sheet, top most, and bottommost. The square or four-sided sheets had beenfused or engrossed. So that, the steadiness of the drone had been maintained and assist as a non-flexible base to the AAD. Both the metal sheets and the eight rods are acted towards surface, where the load had been spread over consistently. So that the drone weight had been balanced consistently. The $60 \times 60 \times 2 \mathrm{~mm}$ of the dimension of circular rod, usually made up of stainless steel is employed to make the four rods which are cylindrical. The two motors had been included in mainframe attopmost and bottommostover reach and every end of the hollow usually circular section. The thrust had been provided to fly and lift the AAD with the help of 16 motors, which balances $1000 \mathrm{~kg}$, approximately. 


\subsection{Electronic Components}

The forecasted AAD had been flying through the mode of automatic pilot. These encompass an automatic pilot basic structure, which employed to regulate the path of the plane without astablepractical control through a survival controller being mandatory in the ground station. The AAD had been controlled through the automatic pilot system. The view point of broader operations like trajectory monitoring systems and meteorological conditions had been focused through these systems.

\subsection{Propulsion System}

As per weight, the extreme thrust had been computed. The drone desires to lifta $1000 \mathrm{~kg}$ of extreme weight, approximately. Amain-frame, which consists of four rods that are cylindrical, had been included in AAD. So, two BLDC at topmost, and bottom most had been determined to practice over each and every end of the pole. Hence, 1000 $\mathrm{kg}$ of AAD had been lifted through a total of sixteen propellerswhich is two-blade and sixteen motors. Later, $20 \mathrm{~kW}$ of the power is required foreach and every motor. The Lithium polymer battery, which is able to recharge had been employed in forecasted AAD and acted towards, as main electricity supply for the automobile. An electric battery had been employed for controls and additional apparatus, and also providesthe powersupplied for the live apparatus and open-air system. The two batteries are interconnected. So that, the power had been supplied for the entire sixteen motors for a $30 \mathrm{~m}$ flight.

\subsection{Robotic Arm}

The AAD is integrated with a handling device (as observed in Figure 6). So that, these devices are employed to lift the citizens in dissimilarcircumstances like the field of battle, to perform protecting secret task, and so on. A handling device named asthe robotic armwhich is programmed generally. These arms featuresand look are unique to the human arm. These arms have thumbs and fingers like humans. These arms are considered as entire of the module or a part of a numerous complicated robot. The robots have two handling devices that are retained equally into inside the AAD's base. It is proven to be when it moves near by the injured person, who had been rescued. The arm computes the physique of the human and carries the humans through single-arm below the roll neck and the other is below the partition ofthe thigh. The human is balanced and placed in a position correctly over the trolley, which subjected to control the action from the hospital, medical camp, and so on.

The forecasted design of AAD's dimensions is calculated and presented in detail in Figure 4. Considering the components and calculations discussed above, the design had been developed in Fusion 360 software. A view of the novel AAD designed is presented in Figure 5.

The squad, arms and transportation of goods to field of battle, saving processes during risk of fire in building which is raised highly, saving processes and carriage during flooding and natural disasters, citizens, transportation of cargo, unpleasant circumstances in overseas drill foroil, unpleasant circumstances in craft and fishing vessels, used as fire extinguisher in farming exploration, transportation of organand so on are the other real-world applications of AAD. A representative sketch for the primary application of AAD is existing in Figure 6. 


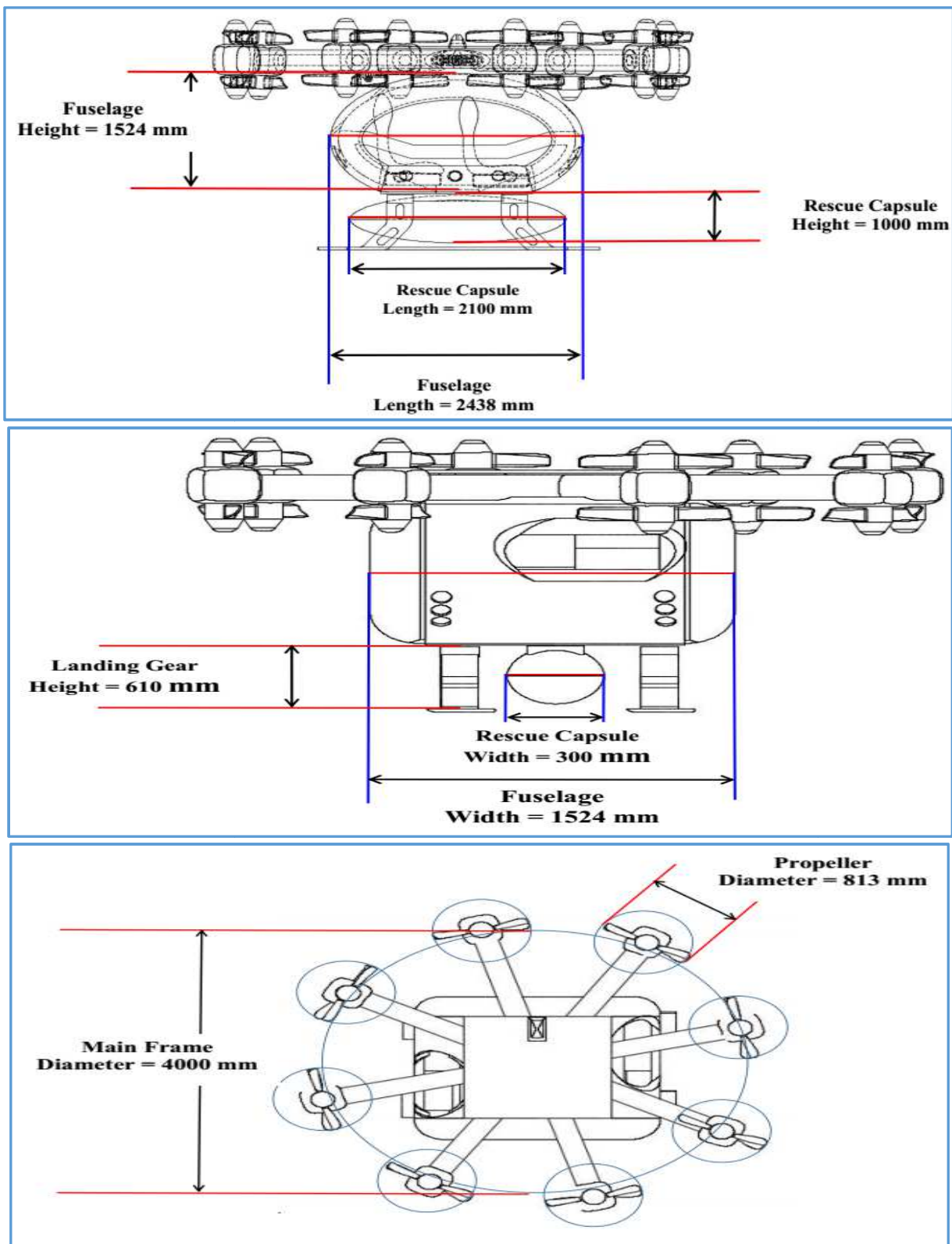

Figure 4: Calculated Dimensions for Proposed AAD Design.

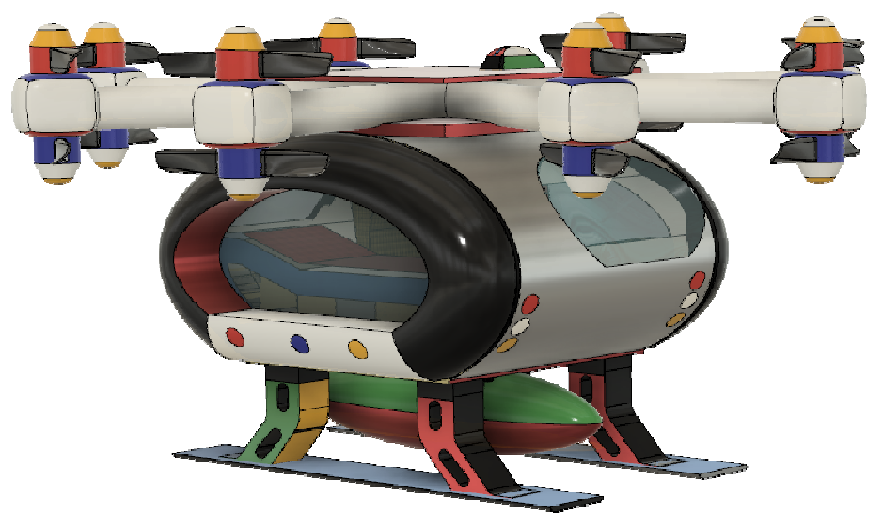

Figure 5: The Novel Conceptual Design of AAD. 

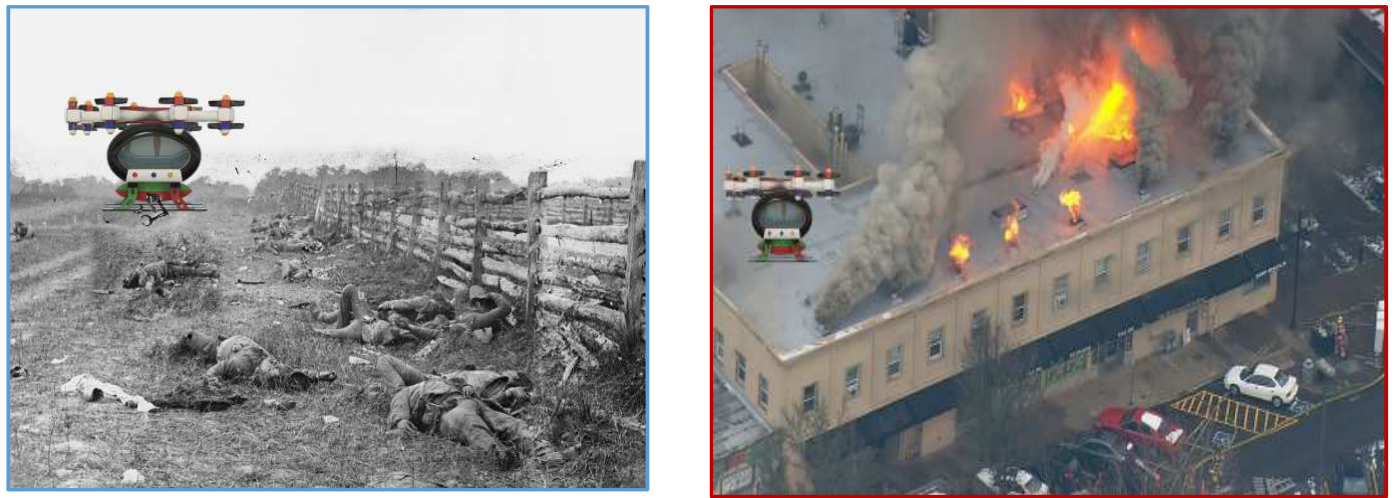

Figure 6: Surveillance and Casualty Evacuation using AAD having a Robotic Arm.

\section{CONCLUSIONS}

Thus, the conceptual design of AADis most significant that exists in reality, had been presented and deliberated the several views of the uncrewed $\mathrm{AAD}$ in the present work. The design calculations are presented in detail and the designed model employing Fusion 360 software also presented. These are very much necessary to fabricate such an unscrewed AAD, havingthe ability to perform an operation to handle numerous activities like vigilance, saving people, any unpleasant circumstances and evacuation of wounded.

\section{REFERENCES}

1. C. H. Setjo, B. Achmad, Faridah. (2017). Thermal image human detection using Haar-cascade classifier. 7th International Annual Engineering Seminar (InAES). 1-6.

2. Kavitha, M., Reddy, A. S., \& Reddy, D. M. Power Quality Improvement Using Fuzzy Logic Controller based CMLI and Fact Devices for Modern Power Systems.

3. C Li, F Chen, F Qi, M Liu, Z Li, F Liang, et al. (2016). Searching for Survivors through Random Human-Body Movement Outdoors by Continuous-Wave Radar Array. PLoS ONE. 11(4): e0152201.

4. Karthik, P., Ranjith, P. S., \& Jayaganesh, M. (2014). Scce: Secure Communication Based on a Chaotic System for Modern Wireless Communication. International Journal of Research in Engineering \& Technology, 2(3), 163-172.

5. Li Chuantao, Chen Fuming, Jin Jingxi, LvHao, Li Sheng, Lu Guohua, Wang Jianqi, et al. (2015). A Method for Remotely Sensing Vital Signs of Human Subjects Outdoors. Sensors (Basel, Switzerland) 15(7): 14830-44.

6. Jalaludin, J., Nordiyana, M. S., \& Suhaimi, N. F. (2014). Exposure to indoor air pollutants (formaldehyde, VOCs, ultrafine particles) and respiratory health symptoms among office workers in old and new buildings in Universiti Putra Malaysia. International Journal of Applied and Natural Sciences, 3(1), 69-80.

7. J. Li, Z. Zeng, J. Sun, F. Liu. (2012). Through-Wall Detection of Human Being's Movement by UWB Radar. IEEE Geoscience and Remote Sensing Letters. 9(6). 1079-108.

8. Y. Zhong, Z. Zhou, T. Jiang, M. Heimlich, E. Dutkiewicz, G. Fang. (2016). Classification of animals and people based on radio-sensor network. 2016 16th International Symposium on Communications and Information Technologies (ISCIT). $113-116$.

9. Parab, V. V. Glimpses of Modern India in Gita Mehta's 'Snakes and Ladders'.

10. J. A. Nanzer, R. L. Rogers. (2007). Human Presence Detection Using Millimeter-Wave Radiometry. IEEE Transactions on Microwave Theory and Techniques. 55(12). 2727-2733. 
